\title{
EDUCAÇÃO, IGREJA E ESTADO NOVO (1937 - 1945): ENSINO SECUNDÁRIO CONFESSIONAL NA PARAÍBA
}

\author{
Vitor de Assis NeVES \\ VÍVIA de Melo SiLVA \\ Universidade Federal da Paraíba (UFPB), João Pessoa, Paraíba, Brasil
}

\begin{abstract}
Resumo: O propósito deste artigo é discutir a predominância de estabelecimentos confessionais de ensino secundário na Paraíba, no período do Estado Novo. A pesquisa histórico-educacional foi desenvolvida conforme os seguintes procedimentos teórico-metodológicos: análises bibliográficas, dentre as quais destacamos as obras de Abreu (2005), Dallabrida (2009), Horta (2012), Mello (1996) e Cunha (2017); levantamento documental em dois arquivos históricos localizados na cidade de João Pessoa, e análise da documentação. Dessa forma, concluímos que $69 \%$ dos estabelecimentos educacionais identificados eram de natureza confessional, o que evidencia a força e influência da Igreja na sociedade paraibana na época.
\end{abstract}

Palavras-chave: Ensino Secundário. Estado Novo. Escolas Confessionais. Paraíba.

\section{INTRODUÇÃO}

O presente texto é resultado da execução do projeto de pesquisa "O Ensino Secundário na Paraíba durante o Estado Novo (1937 - 1945)", desenvolvido no período de agosto de 2017 a julho de 2018, vinculado ao Programa de Iniciação Científica (PIBICCNPQ) de uma instituição de ensino superior federal'.

Este artigo envereda pelo campo da História da Educação do Brasil e tem como objetivo geral apresentar a atuação da igreja no que diz respeito à oferta do ensino secundário no estado da Paraíba (PB) em ocasião do imponente Estado Novo, chefiado por Getúlio Vargas.

A pesquisa histórico-educacional foi desenvolvida por meio dos seguintes procedimentos teórico-metodológicos: análises bibliográficas, dentre as quais destacamos as obras de Bomeny (1999), Cunha (2017) Horta (2012), Pandolfi (1999) e Silva (2014); e levantamento documental nos arquivos históricos situados no Instituto Histórico e Geográfico da Paraíba (IHGP) e na Fundação Espaço Cultural (FUNESC), localizados na cidade de João Pessoa, PB, onde procedemos, atenciosamente, a uma localização e catalogação de textos e anúncios publicados no Jornal $A$ União². Posteriormente, iniciamos o processo de seleção e análise dessa documentação, procurando sempre dia- 
logar com a bibliografia analisada no sentido de adotar uma postura crítica diante dos nossos achados.

Dessa forma, identificamos a predominância de escolas secundárias confessionais no contexto da Paraíba estadonovista. Também evidenciamos o papel ideológico da igreja no sentido de contribuir na conservação do regime vigente. Ademais, explicitamos a relevância e influência educacional, social, econômica e política de algumas das instituições paraibanas abarcadas neste estudo.

No que diz respeito à estrutura deste trabalho, além desta introdução, apresentamos, inicialmente, um panorama geral quanto à presença da igreja na sociedade e educação brasileira à época. Em seguida, a discussão torna-se mais específica, concernente à influência religiosa no ensino secundário do estado da Paraíba. Por fim, ressaltamos as considerações finais.

\section{A PRESENÇA DA IGREJA NO ESTADO NOVO (1937-1945)}

O momento histórico da Terceira República Brasileira ou simplesmente Estado Novo, como é mais conhecido o período entre 10 de novembro de 1937 a 29 de outubro de 1945, foi liderado e conduzido pelo presidente Getúlio Vargas. Ao descrever este regime, o qual foi instituído mediante um golpe de estado, Pandolfi (1999) enfatiza a centralização política como um atributo característico de regimes autoritários, bem como o intervencionismo estatal para consolidar a interferência direta do estado na economia do país. Corroborando com este pensamento, George (2008) acrescenta a esse controle estatal as questões educacionais e sociais.

Como colunas do Estado Novo, além das forças armadas, Cunha (2017) e Horta (2012) expressam que a igreja católica atuou de maneira intensa para a sustentação do regime estadonovista. A respeito do ensino religioso, é preciso retroceder um pouco antes de 1937 para entender esse movimento no período.

No ano de 1931, de acordo com Horta (2012), Dom Leme, o Padre Leonel França e o Ministro da Educação Francisco Campos elaboraram um projeto para reintrodução do ensino religioso nas escolas públicas. Posteriormente, o projeto foi encaminhado e promulgado por Getúlio Vargas em 30 de abril do mesmo ano.

Conforme Cunha (2017),

Para que essa disciplina fosse oferecida nos estabelecimentos oficiais de ensino, pelo menos 20 alunos deveriam estar dispostos a se inscrever nela. O Ministro da Educação Francisco Campos [...] justificou o retorno desse conteúdo ao currículo da escola pública como sendo uma conquista do Catolicismo contra o dogma da liberdade de pensamento defendido por liberais, e, provisoriamente, pelos comunistas, supostamente interessados em destruir as instituições nacionais (CUNHA, 2017, p. 508).

$\mathrm{Na}$ exposição de motivos para justificar a reintrodução do ensino religioso, Francisco Campos afirma que o papel da escola não é somente instruir, todavia educar de modo a "formar homens que, na vida doméstica, profissional e cívica sejam cumpridores fiéis de todos os seus deveres" (BEOZZO, 1984 apud HORTA, 2012, p. 89). 
É nessa perspectiva que o ensino religioso começa a ser identificado, como meio de promover a formação moral do cidadão. Dessa maneira,

Francisco Campos estava não somente atendendo às exigências dos educadores católicos, que reclamavam para a Igreja essa tarefa, como também sendo fiel à sua concepção autoritária, procurando estabelecer mecanismos para reforçar a disciplina e a autoridade. (HORTA, 2012, p. 89).

Segundo Horta (2012), Campos ressaltava que a educação com enfoque maior ao ensino religioso significaria um meio de recuperação de determinados valores, quais sejam: valores ligados à religião, à pátria e à família.

Contudo, a Constituição dos Estados Unidos do Brasil, de 10 de novembro de 1937, em seu artigo 133, anuncia:

O ensino religioso poderá ser contemplado como matéria do curso ordinário das escolas primárias, normais e secundárias. Não poderá, porém, constituir objeto de obrigação dos mestres ou professores, nem de freqüência compulsória por parte dos alunos (BRASIL, 1937).

Assim, é possível dizer que essa natureza facultativa começava a assombrar e "enfraquecer" o ensino da religião cristã - pelo menos nas escolas públicas, obviamente. Comentando essa questão, Horta (2012) expressa:

A constituição de 1937 [...] mantém o dispositivo da Constituição de 1934 relativo ao ensino religioso, mas diminui muito o seu alcance. Enquanto a Constituição de 1934 tornava obrigatória a inclusão desse ensino no horário escolar, mantendo facultativa a frequência, na Constituição de 1937 era a própria inclusão do ensino religioso que se tornava facultativa (HORTA, 2012, p. 109, 110).

Aparentemente, a influência da igreja na educação e na sociedade ficou enfraquecida com o que estava citado no artigo 133 da Constituição de 1937, todavia, conforme aponta Bomeny (1999), o governo não poderia se desentender com a igreja católica porque, nessa época, "estava [...] em posição especialmente desfavorável pelo escasso número de escolas oficiais. [E] quanto às escolas privadas, boa parte era confessional, e nelas a presença da Igreja Católica não era nada desprezível" (BOMENY, 1999, p.161). Corroborando com esta afirmação, no próximo item deste trabalho, é possível perceber que a igreja católica era a responsável pela maioria das escolas secundárias também em solo paraibano.

Estado e Igreja, na prática, trabalhavam em um sistema de cooperação recíproca, qual seja: a igreja recebia ajuda financeira do estado para manter suas escolas, orfanatos, hospitais, entre outros estabelecimentos e em troca, através de seu alcance em massa, colaborava com o governo em nome da "justiça social", manifestando-se explicitamente em favor do governo e de suas ideologias - o que exercia e exerce notório poder de influência sobre os fiéis.

Considerando o recorte temporal focalizado neste estudo, é pertinente ressaltar que o ensino secundário estava organizado oficialmente no Brasil, e de forma específica, mediante dois dispositivos legais, quais sejam: o Decreto №. 19.890 de 18 de abril de 1931, 
mais conhecido como Reforma Francisco Campos, como também, a partir de 09 de abril de 1942, pelo Decreto-Lei №. 4.244, ou simplesmente Lei Orgânica do Ensino Secundário, assinada por Gustavo Capanema.

A Reforma Francisco Campos dispôs sobre os níveis secundário, comercial e superior. De acordo com esta legislação, o ensino secundário abrangeria dois cursos, o fundamental, com duração de cinco anos, e o complementar, com duração de dois anos (BRASIL, 1931).

Zotti (2006) evidencia que, com um currículo enciclopédico, o ensino secundário manteve a lógica propedêutica. Essa especificidade do currículo, evidentemente, se apresentava como mais uma barreira de acesso/permanência dos menos favorecidos economicamente nessa modalidade de ensino. Os jovens que conseguiam ultrapassar "a peneira", que era o exame de admissão, posteriormente, teriam de enfrentar e conciliar uma intensa rotina de estudos com a de trabalho. Nesse sentido, de acordo com a autora citada, os que tinham a oportunidade de continuar os estudos, em sua maioria, optavam pelo ensino comercial, que tinha como finalidade primeira a inserção no mercado de trabalho.

No Decreto-Lei de Gustavo Capanema, a organização do ensino secundário foi dividida em dois ciclos. O primeiro ciclo, com duração de quatro anos, correspondia ao curso ginasial que, em consonância com esta Lei, destinava-se a estabelecer os elementos fundamentais do ensino secundário. $O$ segundo ciclo, colegial, dizia respeito aos cursos clássico e científico, ambos com duração de três anos, que objetivavam a consolidação, 0 desenvolvimento e o aprofundamento da educação ministrada no primeiro ciclo. Conforme a letra desta Lei,

As disciplinas dos cursos Clássico e Científico [...] foram agrupadas de acordo com as áreas do curso ginasial, sendo elas: Línguas (português, latim, grego, francês, inglês e espanhol); Ciências e Filosofia (matemática, física, química, biologia, história geral, história do Brasil, geografia geral, geografia do Brasil e filosofia); Artes (desenho) (BRASIL, 1942).

Assim, o curso clássico, mediante seu currículo, promoveria uma formação intelectual, com um maior estudo e conhecimento de filosofia e das letras antigas. Por sua vez, o curso científico, como o próprio nome já diz, possibilitaria uma formação fincada no âmbito das ciências.

Na primeira Lei não se tinha explicitamente as finalidades do ensino secundário, o que na Reforma Capanema, em seu Art. 10, ficava bastante evidente o seguinte:

1. Formar, em prosseguimento da obra educativa do ensino primário, a personalidade integral dos adolescentes. 2. Acentuar a elevar, na formação espiritual dos adolescentes, a consciência patriótica e a consciência humanística. 3. Dar preparação intelectual geral que possa servir de base a estudos mais elevados de formação especial (BRASIL, 1942). 
Com a reforma de Gustavo Capanema, o ensino religioso passa a ganhar oficialmente mais um espaço no ensino secundário no Brasil, quando é dedicado o capítulo VI da mencionada lei para deliberação deste ensino. Neste sentido, é enaltecido - ensino religioso, destacando que "constitui parte integrante da educação da adolescência, sendo lícito aos estabelecimentos de ensino secundário incluí-lo nos estudos do primeiro e do segundo ciclo" (BRASIL, 1942).

No artigo 21 da Lei Orgânica do Ensino Secundário, o ensino da religião foi enfatizado como sendo essencial para a educação e formação da juventude. Nessa perspectiva, poderia ser incluído tanto no primeiro quanto no segundo ciclo das escolas públicas e privadas. Os aspectos relativos aos programas de ensino e o regime didático foram esclarecidos no parágrafo único do capítulo VI como sendo de responsabilidade exclusiva da autoridade eclesiástica, acentuando, dessa forma, a presença da igreja na deliberação de processos didático-pedagógicos neste nível de ensino do país.

Segundo Neto (2016), todo esse movimento de ampliação do ensino religioso no Brasil, oportunizado durante o governo de Getúlio Vargas, não era por acaso, obviamente. Na verdade, para Vargas, "as veiculações de valores cristãos constituiriam uma base para legitimar seu governo autoritário" (NETO, 2016, p. 234).

Conforme esclarece Zotti (2006), era imprescindível para o governo atender aos interesses da igreja - nesse caso específico, a reintrodução do ensino religioso principalmente por levar em consideração que esta representava um grupo de notória influência na sociedade, sendo também uma forte aliada no combate ao comunismo, principal inimigo do regime vigente.

Ainda a respeito da Lei Orgânica do Ensino Secundário, Silva (2014) evidencia que ela apresentava uma demasiada ênfase na formação moral e no desenvolvimento de uma consciência patriótica, humanística e cultural. Tendo em vista isso, a igreja e, consequentemente, o ensino da religião católica eram de grande valia para a promoção dessa formação.

Assim, Zotti (2006) expressa que essa legislação sobreveio como um meio de fortalecimento da dualidade educacional brasileira, a qual vinha sendo afirmada há certo tempo por Francisco Campos.

Para entender melhor o âmbito de maior circulação das ideias antes apresentadas, vale ressaltar o que o professor Norberto Dallabrida (2009) define acerca do ensino secundário com as seguintes palavras:

Ensino secundário era o nível de escolarização entre o curso primário e o ensino superior [...]. Tratava-se de um longo ciclo de escolarização entre a escola primária e o ensino superior, que, grosso modo, era dirigido às elites e partes das classes médias (DALLABRIDA, 2009, p. 186).

No tocante às definições e características do ensino secundário, na mesma perspectiva, o estudioso Jayme Abreu (2005) aponta:

O termo escola secundária, no Brasil, em seu sentido técnico, corresponde a segunda grande divisão da escala educacional, de cujo tronco (ensino médio) é o ramo julgado mais importante. Em tempos não muito remotos o seu conceito não era o de escola também destinada às classes populares e sim de escola de classe 
dominante, preparatória para os estudos superiores de uma elite (ABREU, 2005, p. 43).

Portanto, essas reflexões nos ajudaram a compreender a posição social, política e econômica que o ensino secundário ocupava e representava em nosso país, sobretudo no período estudado, bem como os interesses e ideologias que o circundavam. Com esse entendimento, vale ressaltar as investidas da igreja católica para concretizar sua influência na formação dos futuros dirigentes nacionais.

A seguir, a discussão abordará de maneira mais caracterizada o contexto da Paraíba, exclusivamente no que concerne às instituições secundárias.

\section{AS INSTITUIÇÕES SECUNDÁRIAS CONFESSIONAIS NA PARAÍBA (1937-1945)}

Nesta seção apresentamos as instituições confessionais de ensino secundário que estavam em pleno funcionamento no estado da Paraíba no período do Estado Novo. A título de informação, além dessas que estão apresentadas no quadro abaixo, em nossa pesquisa também encontramos duas escolas secundárias públicas: o Lyceu Parahybano fundado em 1836, ativo em nossos dias - e a Escola Secundária do Instituto de Educação - em funcionamento entre 1935 e 1939.

Para a elaboração do quadro que segue, utilizamos os achados resultantes das pesquisas empreendidas no Jornal A União, no recorte temporal de 1937 a 1945, como também algumas informações contidas no livro "Evolução do Ensino na Paraíba", de Mello (1996).

QUADRO 1 - Instituições Confessionais de Ensino Secundário na Paraíba (1937 - 1945)

\begin{tabular}{|c|c|c|c|c|}
\hline INSTITUIÇÃO & CIDADE & $\begin{array}{c}\text { ANO DE } \\
\text { FUNCIONAMENTO }\end{array}$ & $\begin{array}{c}\text { ANO DE } \\
\text { MEÇão } \\
\text { NO } \\
\text { JORNAL }\end{array}$ & CATEGORIA \\
\hline $\begin{array}{c}\text { Collegio } \\
\text { Diocesano Pio X }\end{array}$ & $\begin{array}{c}\text { João } \\
\text { Pessoa }\end{array}$ & 1894 & 1937 & Privado \\
$\begin{array}{c}\text { Collegio Nossa } \\
\text { Senhora da Luz }\end{array}$ & Guarabira & - & 1937 & Privado \\
\hline $\begin{array}{c}\text { Collegio de } \\
\text { Nossa Senhora } \\
\text { das Neves }\end{array}$ & $\begin{array}{c}\text { João } \\
\text { Pessoa }\end{array}$ & $1895-2002$ & 1937 & Privado \\
\hline $\begin{array}{c}\text { Collegio da } \\
\text { Sagrada Família }\end{array}$ & $\begin{array}{c}\text { João } \\
\text { Pessoa }\end{array}$ & - & 1937 & Privado \\
\hline
\end{tabular}




\begin{tabular}{|c|c|c|c|c|}
\hline $\begin{array}{c}\text { Gymnasio } \\
\text { Carneiro Leão }\end{array}$ & - & - & 1937 & Privado \\
\hline $\begin{array}{c}\text { Collegio } \\
\text { Diocesano Padre } \\
\text { Rolim }\end{array}$ & Cajazeiras & - & 1937 & Privado \\
\hline $\begin{array}{c}\text { Colégio Monte } \\
\text { Carmelo }\end{array}$ & Princesa & - & 1938 & Privado \\
\hline $\begin{array}{c}\text { Colégio do } \\
\text { Sagrado Coração } \\
\text { de Jesus }\end{array}$ & Bananeiras & $1918-1975$ & 1941 & Privado \\
\hline $\begin{array}{c}\text { Colégio Pio XI } \\
\text { Campina } \\
\text { Grande }\end{array}$ & $1931-2004$ & 1943 & Privado \\
\hline $\begin{array}{c}\text { Colégio Seráfico } \\
\text { João } \\
\text { Pessoa }\end{array}$ & $1929-1940$ & - & Privado \\
\hline $\begin{array}{c}\text { Colégio Nossa } \\
\text { Senhora do } \\
\text { Rosário }\end{array}$ & $\begin{array}{c}\text { Alagoa } \\
\text { Grande }\end{array}$ & 1919 & - & Privado \\
\hline
\end{tabular}

Fonte: Quadro construído mediante publicações do Jornal A União (1937-1945) e Mello (1996).

No quadro acima, apresentamos os nomes de onze (11) instituições confessionais que ofertavam pelo menos um curso do ensino secundário no período. Assim, é preciso dizer algumas informações para facilitar a compreensão do mesmo: os espaços marcados com um traço (-) indicam que nós não encontramos nem nos jornais, nem em Mello (1996) e nem nos arquivos pesquisados os dados cabíveis no item; as duas últimas instituições citadas na tabela foram localizadas na publicação de Mello (1996), por isso, não se têm as informações relativas ao "ano de menção no jornal"; no momento em que é pedido o "ano de funcionamento", por sua vez, é possível perceber que algumas instituições possuem apenas uma data: isso se justifica porque estes estabelecimentos de ensino continuam em atividade em nossos dias.

Além dos estabelecimentos públicos mencionados anteriormente e dos que foram apresentados no quadro, encontramos outras três instituições particulares, quais foram: o Ginásio Campinense, o Collegio 7 de Setembro e o Instituto Pedagógico (também denominado Ginásio Alfredo Dantas).

A respeito do Ginásio Campinense, ressaltamos que não encontramos explicitamente nos Jornais - ou em outros meios - informações sobre a categoria da instituição, porém, com base nas leituras realizadas e na pesquisa de Silva (2014), tudo indica que era uma instituição privada. Possivelmente, esse ginásio também não estava vinculado a nenhuma ordem religiosa. 
Desse modo, das dezesseis (16) instituições secundárias identificadas, onze (11) eram pertencentes a ordens religiosas, $O$ que representa, em porcentagem, aproximadamente $69 \%$ dos estabelecimentos. A amostra de instituições que identificamos tem sua validade e relevância confirmada mediante uma matéria identificada no Jornal $A$ União.

Em 17 de maio 1940, no Jornal A União, encontramos a seguinte publicação: “O Ensino no Brasil". Atinente ao histórico do desenvolvimento do ensino em nosso país, o texto apresenta alguns dados nacionais gerais sobre o número de instituições escolares em funcionamento, a quantidade de alunos matriculados, a porcentagem de professores dos sexos masculino e feminino, entre outras informações.

Visto isso, concernente ao funcionamento do ensino secundário especificamente no estado da Paraíba, é dito brevemente que no ano de 1935 "funcionavam em 20 unidades, com 1798 alunos" (O ENSINO NO BRASIL, 1940, n. 109, p. 7), uma quantidade bem próxima da qual identificamos.

Retomando a fala anterior, em que evidenciamos no contexto paraibano a predominância de instituições de ordem confessional, vale dizer que, ao contrário das escolas laicas, as escolas confessionais são vinculadas ou pertencentes a igrejas ou confissões religiosas. Nessa direção, de acordo com Mello (1996), o Colégio Seráfico era pertencente à Ordem Franciscana de João Pessoa; o Colégio Diocesano Pio X era dirigido pelos irmãos Maristas; o Colégio Nossa Senhora das Neves foi fundado por D. Adauto Aurélio de Miranda Henriques e, posteriormente, passou a ser dirigido pela Comunidade da Sagrada Família. O Colégio Pio XI, de Campina Grande, equiparado ao Colégio Pedro II, foi fundado pelo Padre José Delgado.

De acordo com Horta (2012), a conjuntura vivida em todo o Brasil, no período, era notoriamente complexa, pautada na doutrinação e uniformização da sociedade. Assim sendo, a presença da igreja e do ensino religioso, implementado oficialmente com a Reforma Capanema (1942), contribuía para essa condução da sociedade, com procedimentos ajustados à moral e ao civismo.

Com escolas religiosas de alto padrão social, tendo algumas o reconhecimento federal, obviamente, todo esse movimento nacional era repercutido no estado da Paraíba.

Horta (2012) também evidencia que tal ênfase na moral do cidadão, primeiramente, foi consolidada mediante a presença da igreja com o ensino religioso nas escolas e, posteriormente-ocasionando certo encontro entre igreja e exército-, por meio da inserção dos princípios de civismo e patriotismo. A educação, dessa forma, continuava a acentuar a histórica dualidade da educação brasileira:

Para o povo, para as massas brutas, para as crianças - hábitos morais, moralidade prática, automatismo ético. Mas para os dirigentes, para as elites, para os responsáveis pela orientação da vida pública, para os que vão formar a alma nacional - não só a mecanização dos atos, mas o preparo integral. Para eles importa a moral ciência (ALBA CANIZARES NASCIMENTO apud Associação..., 1999 apud HORTA 2012, p. 124). 
Destarte, é possível falar que a massa popular era moldada, minuciosamente, para obedecer às elites governantes reproduzindo suas vontades, enquanto as elites eram formadas para dirigir a nação, o povo. Nesse mesmo sentido, ainda conforme Horta (2012) e as pesquisas no Jornal $A$ União, Getúlio Vargas, em seus discursos, costumava relacionar a "educação do povo" com a "glorificação da Pátria", afirmando que somente quando o povo estivesse educado o Brasil se tornaria uma grande pátria.

No que diz respeito à influência e importância das instituições confessionais na Paraíba, tivemos alguns achados importantes sobre algumas delas. Em 1937, no dia 08 de janeiro, ao Collegio de Nossa Senhora das Neves foi conferida inspeção preliminar: "Por despacho do sr. Ministro da Educação, datado de 8 deste, foi concedido inspeção preliminar ao acreditado Collegio de Nossa Senhora das Neves, desta capital" (VIDA ESCOLAR, 1937, n. 313, p. 3).

No ano de 1938, especificamente no dia 22 de dezembro, identificamos no jornal A União a equiparação permanente do Colégio Diocesano Pio $\mathrm{X}$ ao Colégio Pedro II. Localizado na capital paraibana, João Pessoa, a instituição era regida pela "Arquidiocese, sob a direção de sacerdotes do clero secular" (COLÉGIO DIOCESANO PIO X EQUIPARADO AO PEDRO II, 1938, n. 260, p.4). Com a notícia da equiparação, é dito que o referido colégio "continua guardando a sua posição de merecido relevo nos meios educacionais do país" (COLÉGIO DIOCESANO PIO X EQUIPARADO AO PEDRO II, 1938, n. 260, p.4). Neste sentido,

Após o parecer unanime do Consêlho Nacional de Educação, lhe foi concedida a inspeção permanente com o título de Estabelecimento livre de Ensino secundário, por decreto do Exmo. Sr. Presidente da República sob número 1,182, datado de 18 de outubro do corrente ano (COLÉGIO DIOCESANO PIO X EQUIPARADO AO PEDRO II, 1938, n. 260, p.4).

Nessa perspectiva, apontamos que o Colégio Diocesano Pio X era o único ginásio privado da Paraíba, no período, a possuir a inspeção permanente, com base na Reforma Francisco Campos.

Um símbolo de grande importância e desenvolvimento no interior da Paraíba no período estudado foi o Colégio Padre Rolim. Portanto, explicitamos, neste momento, algumas considerações encontradas concernentes ao seu "10 Centenário" ( $O 1^{\circ}$ CENTENARIO DO COLLEGIO PADRE ROLIM, 1937, n. 124, p. 1).

Na publicação relativa à comemoração do centenário de fundação do Colégio Padre Rolim - estabelecimento situado na cidade de Cajazeiras-PB -, pode-se identificar a importância do educandário não somente para o município, mas também para o estado quando o Interventor Argemiro de Figueiredo, além de enviar um representante para participar de todas as cerimônias e homenagens, "decretará feriado estadual o próximo dia 22", também nota-se, neste mesmo dia que "A União dedicará a sua edição ao nome do padre Rolim e suas marcantes realizações educacionais" (O CENTENARIO DA FUNDAÇÃO DO COLLEGIO PADRE ROLIM, 1937, n. 154, p. 1, grifo nosso).

Sobre o histórico do Colégio, expressa:

Fundado, ha cem anos passados, uma casa de ensino, em pleno coração da gleba parahybana, padre Rolim tornou-a, depois, um centro de irradiação intellectual por todo o Estado, projectando, mesmo, o seu valor fóra dos nossos recantos. 


\begin{abstract}
Alii, se acolheram radiosas expressões da intelligência parahybana, os membros das mais tradicionaes familias do Estado e estranhos, que, atraídos pelo renome do Padre Rolim, conquistado á custa de uma admirável actuação no magistério de Recife, receberam delle os seus primeiros ensinamentos.

O Collegio Padre Rolim não foi, apenas, uma escola plantada no sertão parahybano. Marca uma época na historia da instrução em nossa terra. Assignala, ainda, a formação de uma importante cidade, cujas primeiras casas que se iniciaram á sombra do Collegio (O CENTENARIO DA FUNDAÇÃO DO COLLEGIO PADRE ROLIM, 1937, n. 154, p. 1).
\end{abstract}

Conforme apresentado, a história do Colégio Padre Rolim pode até se confundir com a história da própria cidade de Cajazeiras, tanto pelo tempo de sua fundação quanto pela influência que este acontecimento causou, considerando que "as primeiras casas foram se edificando á proporção que a fama do Collegio chegava a todos os recantos do Estado" (O CENTENARIO DA FUNDAÇÃO DO COLLEGIO PADRE ROLIM, 1937, n. 154, p. 1).

Dessa forma, a referida instituição pode ser considerada uma das instituições secundárias mais importantes do período, sendo hoje, para nós, ainda que indiretamente, objeto de estudo para a história da educação paraibana.

Dito isto, conseguimos perceber, sobretudo, a atuação intensa da igreja no desenvolvimento da sociedade paraibana no período, como também no que diz respeito ao seu papel formativo de uma elite intelectual de jovens no estado da Paraíba.

\title{
CONSIDERAÇÕES FINAIS
}

Através deste estudo evidencia-se o importante papel que a igreja católica exerceu no que se refere ao fortalecimento do regime conhecido como Estado Novo. Atuando como um aparelho ideológico, a igreja disseminou os princípios e valores estadonovistas aos fiéis e alunos em todo o território nacional.

O movimento histórico também mostrou algumas nuances na legislação no que se refere ao ensino religioso. De fato, este se manteve presente e com grande alcance de público, tendo em vista que a maioria das escolas secundárias do país pertencia a grupos religiosos. Em 1942, com a implantação da Lei Orgânica do Ensino Secundário, o ensino religioso recebe um impulso para adentrar mais fortemente, também, nas escolas secundárias públicas.

O estado da Paraíba acompanhou o caminho apontado pela conjuntura nacional. Prova disso mostra-se ao identificarmos que, das dezesseis (16) instituições encontradas no Jornal A União (1937 - 1945) e em Mello (1996), onze (11) eram confessionais, representando, aproximadamente, $69 \%$ de estabelecimentos educacionais que ministravam o ensino secundário no estado, o que retrata a força e influência da igreja na sociedade paraibana.

Por fim, destacamos a relevância deste trabalho para a história da educação da Paraíba, o qual apresenta resultados inéditos de um momento histórico evidentemente importante e de um nível educacional - o secundário - que ainda carece de pesquisas por parte dos historiadores educacionais, especialmente na Paraíba. 
Artigo recebido em: 29/01/2019

Aprovado para publicação em: 23/03/2019

\title{
EDUCATION, CHURCH AND NEW STATE (1937 - 1945): SECONDARY CONFESSIONAL EDUCATION IN PARAÍBA
}

\begin{abstract}
The purpose of this article is to discuss the predominance of confessional establishments of secondary education in Paraíba, in the period of New State. The historicaleducational research was developed according to the following theoretical-methodological procedures: bibliographic analyzes, among which we highlight the works of Abreu (2005), Dallabrida (2009), Horta (2012), Melo (1996), Cunha (2017); documentary survey, in two historical archives located in the city of João Pessoa, and analysis of documentation. Thus, we conclude that $69 \%$ of the educational establishments identified were of a confessional nature, which evidences the strength and influence of the Church in the Brazilian society at the time.
\end{abstract}

KEYWORDS: Secondary Education. New State. Confessional Schools. Paraíba.

\section{EDUCACIÓN, IGLESIA Y ESTADO NUEVO (1937-1945): ENSEÑANZA SECUNDARIA CONFESIONAL EN LA PARAÍBA}

RESUMEN: El propósito de este artículo es discutir el predominio de establecimientos confesionales de enseñanza secundaria en Paraíba, en el período del Estado Nuevo. La investigación históricoeducativa fue desarrollada conforme a los siguientes procedimientos teórico-metodológicos: análisis bibliográficos, entre las cuales destacamos las obras de Abreu (2005), Dallabrida (2009), Horta (2012), Melo (1996), Cunha (2017); levantamiento documental, en dos archivos históricos ubicados en la ciudad de João Pessoa, y análisis de la documentación. De esta forma, concluimos que el $69 \%$ de los establecimientos educativos identificados eran de naturaleza confesional, lo que evidencia la fuerza e influencia de la Iglesia en la sociedad paraibana en la época.

PALABRAS CLAVE: Enseñanza Secundaria. Estado Nuevo. Escuelas Confesionales. Paraíba.

\section{NOTAS}

1) Universidade Federal da Paraíba, Centro de Educação, no Campus I.

2) Compõe a imprensa oficial do estado da Paraíba, ainda em circulação, fundado em 1893 por Álvaro Machado.

3) O Colégio Pedro II, conforme explicitado no Decreto №. 19.890/1931, era o estabelecimento padrão de ensino secundário no Brasil no período em foco. Nesse sentido, no referido documento, são apresentados alguns requisitos para que fosse cedida a concessão de equiparação/inspeção para determinado estabelecimento. A equiparação, dessa forma, funcionava como uma certificação de qualidade. Ver mais no Capítulo I do Título II do Decreto №. 19.890/1931. 


\section{REFERÊNCIAS}

ABREU, Jayme. A Educação Secundária no Brasil: Ensaio de identificação de suas características principais. Revista Brasileira de Estudos Pedagógicos, Brasília, v. 86, n. 212, p. 39-84, jan./abr. 2005. Disponível em: http://www.emaberto.inep.gov.br/index.php/RBEP/article/viewFile/75/473. Acesso em: 12 jul. 2017.

BOMENY, H.M. B. Três decretos e um ministério: a propósito da Educação no Estado Novo. In: PANDOLFI, Dulce (org.). Repensando o Estado Novo. Rio de Janeiro: Ed. Fundação Getúlio Vargas, 1999. p. 137-166.

BRASIL. Decreto N. 19.890, de 18 de abril de 1931. Reforma Francisco Campos, Rio de Janeiro, abr. 1931. Disponível em: https://www2.camara.leg.br/legin/fed/decret/19301939/decreto-19890-18-abril-1931-504631-publicacaooriginal-141245-pe.html. Acesso em: 25 maio 2019.

BRASIL. [Constituição (1937)]. Constituição da República dos Estados Unidos do Brasil de 1937. Rio de Janeiro, DF: Presidência da República. Disponível em: http://www.planalto.gov.br/ccivil_03/Constituicao/Constituicao37.htm. Acesso em: 12 maio 2018.

BRASIL. Decreto-Lei n. 4.244, de 9 de abril de 1942. Lei Orgânica do Ensino Secundário, Rio de Janeiro, abr. 1942. Disponível em:

http://www.histedbr.fe.unicamp.br/navegando/fontes_escritas/5_Gov_Vargas/decretolei\%204.244-1942\%20reforma\%20capanema-ensino\%20secund\%E1rio.htm. Acesso em: 12 maio 2018.

COLÉGIO DIOCESANO Pio X Equiparado ao Pedro II. Jornal A União, João Pessoa, Ano XLVI, n. 260, p. 4, 22 dez. 1938.

CUNHA, Luiz Antônio. A educação brasileira na primeira onda laica: do império à república. Rio de Janeiro: Edição do Autor, 2017. Disponível em: https://pantheon.ufrj.br/bitstream/11422/2365/1/AEduca\%C3\%A7\%C3\%A3oBrasileirana PrimeiraOndaLaica.pdf. Acesso em: 09 jun. 2018.

DALLABRIDA, Norberto. A reforma Francisco Campos e a modernização nacionalizada do ensino secundário. Educação, Porto Alegre, v. 32, n. 2, p. 185-191, maio/ago. 2009. Disponível em: http://docplayer.com.br/29644907-A-reforma-francisco-campos-e-amodernizacao-nacionalizada-do-ensino-secundario.html. Acesso em: 20 maio 2018.

GEORGE, Michael. A Educação e o Estado Novo: a ratificação da ordem dominante e a construção do imaginário político brasileiro. Revela, Praia Grande, ano I, n. 2, (p. 1-10), mar. 2008. Disponível em: 
NEVES, V. A.; SILVA, V. M

http://fals.com.br/revela/REVELA\%20XVII/educacaoestadonovo.pdf. Acesso em: 05 dez. 2017.

HORTA, José Silvério Baia. O hino, o sermão e a ordem do dia: Regime autoritário e a educação no Brasil (1930-1945). Rio de Janeiro: Ed. UFRJ, 2012.

MELLO, José Baptista de. Evolução do Ensino na Paraíba. Secretaria da Educação e Cultura. Conselho Estadual de Educação. João Pessoa,: Imprensa Oficial, 1996 (Coleção Biblioteca Paraibana). 202p.

NETO, Ismar Ruffato. Ensino Religioso no Brasil: uma análise sobre as transformações ou não transformações históricas no ensino religioso. In: SEMINÁRIO INTERNACIONAL DE PRÁTICAS RELIGIOSAS NO MUNDO CONTEMPORÂNEO, 4, 2016, Londrina. Anais. Londrina: Universidade Estadual de Londrina, 2016. p. 231-244 Disponível em: http://www.uel.br/laboratorios/religiosidade/anais/index.php/ivleer/iwleer/paper/down load/8/20. Acesso em: 25 abr. 2019.

O CENTENARIO da Fundação do "Collegio Padre Rolim". Jornal A União, João Pessoa, Ano XLV, n. 154, p. 1, 18 ago. 1937.

O ENSINO no Brasil. Jornal A União, João Pessoa, Ano XLVIII, n. 109, p. 7, 17 maio 1940.

O 1. ${ }^{\circ}$ CENTENARIO do Collegio Padre Rolim. Jornal A União, João Pessoa, Ano XLV, n. 124, p. 1, 10 jul. 1937.

PANDOLFI, Dulce (org.). Repensando o Estado Novo. Rio de Janeiro: Ed. Fundação Getúlio Vargas, 1999.

SILVA, Vívia de Melo. Por uma formação da juventude campinense: o Colégio "Gigantão da Prata" (1948-1962). 2014. Tese (Doutorado em Educação) - Faculdade de Educação, Universidade Federal da Paraíba, João Pessoa, 2014.

VIDA ESCOLAR. Jornal A União, João Pessoa, Ano XLIV, n. 313, p. 3, 29 jan. 1937.

ZOTTI, Solange Aparecida. O Ensino Secundário nas Reformas Francisco Campos e Gustavo Capanema: Um Olhar Sobre A Organização do Currículo Escolar. In: IV Congresso Brasileiro de História da Educação, 4, 2006, Goiânia. Anais. Goiânia: Universidade Católica de Goiás, 2006. Disponível em: http://www.sbhe.org.br/novo/congressos/cbhe4/individuaiscoautorais/eixo01/Solange\%20Aparecida\%20Zotti\%20-\%20Texto.pdf. Acesso em: 18 maio 2018. 
Vitor de Assis Neves: Graduando em Pedagogia e Bolsista do Programa Institucional de Iniciação Científica (PIBIC/CNPq) da Universidade Federal da Paraíba (UFPB). Durante o curso, tem se dedicado a pesquisas em História da Educação, com ênfase na História da Educação Paraibana. Membro do Grupo de Pesquisa CIÊNCIA, EDUCAÇÃO E SOCIEDADE e do Grupo de Estudos e Pesquisas HISTÓRIA DA EDUCAÇÃ̃O DA PARAÍBA - HISTEDBR/PB.

ORCID: https://orcid.org/0000-0003-0793-962X

E-mail: assisvitor7@smail.com

Vívia de Melo SILVA: Doutora e Mestre em Educação pelo Programa de Pós-graduação em Educação da Universidade Federal da Paraíba (PPGE/UFPB) e graduada em Pedagogia pela Universidade Federal de Campina Grande (2007). É Professora vinculada ao Departamento de Fundamentação da Educação (DFE) do Centro de Educação (CE) da UFPB - Campus I. É membro do grupo de pesquisa CIÊNCIA, EDUCAÇÃO E SOCIEDADE e do Grupo de Estudos e Pesquisas História da Educação da Paraíba HISTEDBR/PB.

OrCID: http://orcid.org/0000-0002-5476-2938

E-mail:viviafag@smail.com

Este periódico utiliza a licença Creative Commons Attribution 3.0, para periódicos de acesso aberto (Open Archives Iniciative - OAI). 